\title{
The Mediating Role of Resilience and Life Satisfaction in the Relationship between Stress and Burnout in Medical Students during the COVID-19 Pandemic
}

\author{
Ivone Duarte 1,2*, Ana Alves ${ }^{3}$, Ana Coelho ${ }^{3}$, Ana Ferreira ${ }^{3}$, Beatriz Cabral ${ }^{3}$, Bebiana Silva ${ }^{3}$, João Peralta ${ }^{3}$, Juliana \\ Silva ${ }^{3}$, Pedro Domingues ${ }^{3}$, Pedro Nunes ${ }^{3}$, Carla Serrão ${ }^{4,5}$ and Cristina Santos ${ }^{1,2}$ \\ 1 Faculty of Medicine, MEDCIDS-Department of Community Medicine, Information and Decision in Health, \\ University of Porto, 4200-450 Porto, Portugal; iduarte@med.up.pt (I.D.); csantos@med.up.pt (C.S) \\ 2 Faculty of Medicine, CINTESIS-Center for Health Technology and Services Research, 4200-450 Porto, Portu- \\ gal \\ 3 Faculty of Medicine, University of Porto, 4200-450 Porto, Portugal; up201604246@edu.med.up.pt (A.A); \\ up201606355@edu.med.up.pt (A.C); up201508918@edu.med.up.pt (A.F); up201304008@edu.med.up.pt (B.C); \\ up201307835@edu.med.up.pt (B.S); up201604454@edu.med.up.pt(J.P); up200801044@edu.med.up.pt(J.S); \\ up201606261@edu.med.up.pt (P.D); up201504684@edu.med.up.pt (P.N) \\ 4 School of Education-Polytechnic of Porto, 4200-465 Porto, Portugal; carlaserrao@ese.ipp.pt (C.S.S.) \\ 5 School of Education - Centre for Research and Innovation in Education, 4200-465 Porto, Portugal; \\ * Correspondence: iduarte@med.up.pt (I.D.); Tel.: +351-220-426-840
}

\begin{abstract}
Following the WHO's declaration of a public health emergency due to the COVID-19 outbreak, the subsequent quarantine and confinement measures that were adopted, including distance learning measures, were shown to have caused a significant deterioration in the mental health of medical students. The goal of this study was to explore the mediating role of resilience and life satisfaction in the relationship between perceived stress and burnout among medical students in the context of COVID-19. A transversal assessment was performed using an online questionnaire, to which 462 students responded. The instruments applied were the Perceived Stress Scale-10, the Resilience Scale-25 items, the Satisfaction with Life Scale (SWLS) and the Burnout Scale (Oldenburg Inventory). A regression model was estimated for each dimension of burnout. The results revealed that resilience and life satisfaction play a mediating role in the association between stress and the dimensions of burnout. This suggests that measures of promoting mental health based on resilience and improving perceptions of life should be implemented.
\end{abstract}

Keywords: COVID-19; SARS-CoV-2; burnout; stress; resilience; medical students

\section{Introduction}

COVID-19 was first identified in December 2019 in Wuhan, China [1]. On 30 January 2020, the WHO declared the outbreak of the novel coronavirus a public health emergency of international concern, the WHO's highest level of alert [2]. During this unprecedented pandemic era, most countries adopted exceptional and temporary measures regarding the epidemiological situation of the COVID-19 disease. Among these measures, the suspension of in-person teaching activities particularly stands out, with those activities subsequently being offered at a distance through so-called emergency remote teaching [3, 4]. Mandatory confinement, quarantine, isolation and social distancing have already had negative effects on the mental health of the general population, where exponential growth in stress levels and symptoms of depression and anxiety has been observed [3]. Looking at the university context specifically, the Zis et al study of a sample of 154 first- through sixth-year medical students in Cyprus found a significant deterioration in their mental health from the pre- to post-COVID-19 period (pre-COVID-19 $58.8 \pm 21.6$ vs. COVID-19 $48.3 \pm 23, \mathrm{p}<0.001)$ related with the adoption of emergency remote teaching methods [5]. 
In the Australian context, in March 2020 Lyon et al. conducted a study with the goal of evaluating the impact of COVID-19 on the mental health of a sample of 297 medical students. The results indicate that more than two-thirds displayed a deterioration in their mental health [6].

Medical students can experience stress when curricular demands exceed their resources to manage them [7], and a higher prevalence of perceived stress compared to both the general population and students of other academic areas has been reported [8,9]. Furthermore, medical students have a lower likelihood of seeking help, possibly stemming from the stigma associated with this group in particular receiving mental health care [10]. In addition to the level of perceived stress, studies have reported psychosocial consequences, such as increased levels of anxiety and depression, as well as diminished quality of life and an increased prevalence of burnout [11,12]. The study by Saraswathi also demonstrated a significant increase in the prevalence of anxiety (33.2\%) and stress (24.9\%) during the COVID-19 pandemic [13].

If even under normal circumstances it is highly likely that most medical students will be affected by burnout to some degree over the course of their studies [14], it is expectable that the pandemic and the stress factors resulting from the uncertainty and abrupt changes would exacerbate this issue. During the era of the COVID-19 pandemic, many of countries worldwide have adopted very strong measures. The new pandemic scenario, the social isolation, the uncertainty and fear associated with it, the changes arising from the teachinglearning process, namely emergency remote teaching [4], are only some of the factors that may contribute to the increase exhaustion, fatigue and stress in medical students'.

Burnout is a term that was first used by Herbert Freudenberger and described as a mental disorder resulting from prolonged exposure to career-related stress factors, and later defined as a multidimensional occupational syndrome (Burnout Syndrome) [15]. In 2019, the syndrome was included in the International Classification of Diseases as an occupational phenomenon [16]. Added to their study-related workload are the demands and responsibilities imposed upon them due to the nature of their future profession, one dedicated to providing care to humans and thus with a reduced tolerance for error, conditions that favor the development of stress and anxiety [17,18]. A global study, from 12 countries demonstrated alarming high rates of mental health problems, burnout, substance abuse, and mental stress of medical students [19].

Despite the fact that there are studies on burnout in students, little importance has been given to the measure of the construct. In the vast majority of studies, academic exhaustion was measured by the Maslach Burnout Inventory-General Survey (MBI-GS) [20]. Criticism leading several authors to propose alternative assessment tools [21, 22]. Furthermore, some scholars have criticized the psychometric qualities of the MBI-GS [23, 24]. For this reason, we decided to use the Oldenburg Burnout Inventory (OLBI) [25-27].

The Oldenburg Burnout Inventory it was originally developed by Demerouti and Nachreiner, who suggested two burnout dimensions, disengagement and exhaustion, applicable to professions outside human services occupations [28]. It is many versions across vary occupational groups, in Portugal has a version for students. The exhaustion subscale is related to feelings of emptiness, excessive workload, need for rest and physical, cognitive and emotional exhaustion, and the disengagement subscale is related to negative and cynical behaviors and attitudes regarding work [29].

Burnout plays a significant role in the overall wellbeing of medical students, is associated with poor academic performance, sleep disturbance, risk of severe mental illness or substance use disorder [30]. It is important investigate the burnout phenomenon in university students because the research indicates that burnout begins in medical school and continues after graduation [31]. One factor that can explain why some physicians possess the capacity to cope effectively with stress and the ability to bounce back from stressors is resilience [32]. Keeton et al. [33] describe resilience as a protective factors against burnout protection factor and as a variable that cushioned the impact of the negative effects of occupational stressors. West et al. [32] examined a sample of 5445 physicians and concluded that resilience was inversely associated with burnout symptoms. 
The literature defines psychological resilience as the capacity to maintain a state of equilibrium, regardless of the presence of extremely adverse circumstances [34-36]. Another definition points to the ability to respond to stress in a healthy manner, such that goals are achieved with a minimum of psychological and physical distress $[37,38]$. Therefore, resilient individuals are usually prepared to recover from challenges while simultaneously learning and gathering strength from the experience [38]. Similarly, "resilience" refers to the internal resources that the subject possesses to be able to deal with stress factors in a manner that leaves minimal psychological impact, while simultaneously enjoying personal development and building new adaptive mental "tools" [36]. Simply put, resilience is described as an adaptive skill generated by the interaction between individuals and their respective environments [37]. It can be easily understood, then, that psychological resilience is malleable and can be practiced, having recently been identified as a priority in medical training $[13,38,39]$.

To this end, one strategy that could facilitate the development of adaptation mechanisms among medical students might be promoting personal reflection on past experiences and the consequent recognition that not all life events can have positive outcomes [40]. Furthermore, articles suggest that students who report greater commitment to selfcare activities have lower rates of perceived stress and greater quality of life; in other words, those with more balanced lifestyles demonstrate greater resilience [38]. In the same vein, good levels of social belonging, relationships and support are characteristics that contribute to resilience $[41,42]$.

On the one hand, there are studies that demonstrate an association between resilience in medical students and lower levels of psychological distress, greater life satisfaction, happiness, greater quality of life, fewer symptoms of anxiety and a greater subjective perception of well-being [37]. On the other, there are studies that point to higher levels of perceived stress and lower resilience among medical students compared to the general population [38]. For example, a study that included Canadian students stratified by age and gender with controls from the general population found that the former have lower resilience scores than the latter [43]. Given this, it is crucial that research on resilience in medical students continues to be developed so that it can be better characterized and subsequently improved. On another note, it is known that resilience is one factor that can reduce burnout. Therefore, greater resilience is associated with less burnout and greater tolerance for uncertainty [36]. Furthermore, one study found that students who are resilient against burnout, or who recovered from it, have lower levels of stress and fatigue in the first year of follow up compared with students who are experiencing burnout [44]. One article looking at the correlation between academic burnout and the psychological well-being of medical students points to the premise that, the greater the level of burnout, the harder it is for students to make a positive assessment of the present moment [45]. Another article notes the positive correlation between well-being and resilience among Chinese medical students. Moreover, the authors report that the stress factor negatively influenced students' life satisfaction, leading to the development of depression [45]. An important personal characteristic that contributes to resilience is psychological flexibility, which is understood as the individual capacity to develop and maintain full awareness of one's own thoughts and feelings. Psychological flexibility is correlated with greater perceived quality of life and emotional well-being. The same study mentions that medical students who are able to manage their own emotions and thoughts in this way are capable of being more resilient and less prone to psychological distress and burnout [46].

Life satisfaction is a cognitive and global assessment of individuals' quality of life and well-being [47]. Burnout and stress negatively impacts quality of life leading to various negative outcomes. Moreover, previous studies have found that individual subjective well-being is an important variable in attenuating symptoms of stress and Burnout [48]. Thus, subjective well-being is expected to act as a mediator in the relationship between stress and burnout. Regardless of the effects of COVID-19, several studies have already indicated the effect of relationship between burnout, resilience and psychological well-being[11-13]. However, to the best of the authors' knowledge, no study 
has evaluated this relationship in medical students during the COVID-19 pandemic. Thus, this issue deserves particular interest in the context of a pandemic.

Here, we must highlight the necessary role of universities as entities of health promotion, given the symbiotic relationship between health and education. To that end, it is important that university institutions develop strategies to promote mental health that consider students' emotional and psychological needs with the aim of capitalizing on efforts to minimize possible structural risk factors and optimizing students' adaptive mechanisms [46]. Therefore, practicing resilience and investing in well-being becomes increasingly relevant across the various domains of an individual's life [48].

Keeping in mind the existing evidence that resilience appears to be a protective factor against burnout and positively related with life satisfaction, the goal of this study is to explore the mediating roles of resilience and life satisfaction in the relationship between perceived stress and burnout among medical students in the context of COVID-19.

\section{Materials and Methods}

\subsection{Study Design and Participants}

This study performed a transversal assessment of students attending a medical school in northern Portugal. The data were collected through a survey shared through both social media and the school's official communications channels. The data collection period was between 6 May 2020 and 29 May 2020. Responses were collected using the Google Forms platform.

The ethical procedures were carried out in accordance with the Helsinki Declaration, whereby the Ethics Committee of the São João hospital complex analyzed and approved the study (ref. 98/2020). All participants gave their informed consent online, in accordance with the General Directives of the General Data Protection Regulations for clinical research [49].

In total, 462 students responded to the survey, with an average age of 22 (range=1842). Table 1 describes the characteristics of the sample.

Table 1: Medical student characteristics $(n=462)$

n $(\%)$

Sex

Female

Male

Civil status

Married / De facto union

Divorced / Single

Has children

Academic year

$1^{\text {st }}$

$100(22)$

$2^{\text {nd }}$

$3^{\text {rd }}$

$4^{\text {th }}$

67 (14)

$5^{\text {th }}$

$6^{\text {th }}$

Attending this academic year for the $1^{\text {st }}$ time

Holds special status at Faculty

Holds worker-student status

Is living away from home 
Currently living with how many other people

0

1

2

3

4 or more

Physical exercise

Leaves the house how often

Occasionally

1-2 times per week

$\geq 3$ times per week

Means to keep up with classes

Supplements/stimulants

Extracurricular activities

Stressful life event

Psychological support

Has taken a COVID-19 test

No, but would like to

No, doesn't want to

Yes, has the result
15 (3)

44 (10)

124 (27)

189 (41)

90 (19)

$316(68)$

$249(54)$

134 (29)

79 (17)

197 (43)

$203(44)$

84 (18)

$154(33)$

298 (68)

$10(2)$

\subsection{Survey Questionnaire}

The survey comprised 3 separate parts: collecting sociodemographic data, evaluating students' resources and their habits. The psychological variables analyzed were perceived stress, psychological resilience, life satisfaction and burnout.

The Perceived Stress Scale-10 (PSS-10) from Cohen and Williamson [36], adapted to Portugal by Trigo [50] with a good internal consistency (Cronbach's Alpha: 0.874), is a global measure that evaluates to what extent life events are perceived as stress inducers. The studies performed on the Portuguese population concluded that the PSS-10 presents good psychometric qualities, with the Portuguese version having shown to be generally robust, easy to understand, quick to fill out and simple to score. The PSS-10 consists of 10 questions about the frequency (0-never; 1-almost never; 2-sometimes; 3-fairly often; 4very often) with which a general life circumstance has occurred over the last month, without specifying any situation in particular. In the studies on the Portuguese population, an equivalence was established between the scores of the PSS-10 and the respective percentile; raw scores above the $80^{\text {th }}$ percentile were considered indicators of pathology [50].

The Resilience Scale ([35]; adapted by Oliveira \& Machado [51]) consists of 25 items organized according to a 7-point Likert scale (where 1 is "totally disagree", 4 is "neither agree nor disagree", and 7 is "totally agree", referring to the respondent's agreement with each statement); the final score can range from 25 to 175 points, with higher scores indicating higher resilience. A score below 121 is considered indicative of "reduced resilience"; a score between 121 and 145 is considered "moderate resilience" and a score above 145 is considered "high moderate" to "high resilience" [51]. Applied to a sample of higher education students, this scale demonstrated good internal consistency (Cronbach's Alpha: .89). The scoring and interpreting of results were as follows: 25-120 low resilience, 121-145 moderate resilience and 145-175 high resilience.

The Satisfaction with Life Scale [52] aims to evaluate the cognitive component of subjective well-being and is composed of 5 items. Each item is an affirmation to which the respondent must attribute a level of agreement using a 7-point scale (from 1: "strongly disagree" to 7: "strongly agree"). The scale was adapted to the Portuguese population [53] 
with an $\alpha$ of 0.77 . The result of the scale is determined by adding the scores of the five items, ranging from 5 to 25 points. Higher scores suggest greater life satisfaction. This scale is characterized by acceptable and high internal consistency (original version: $\alpha=0.87$ and the Portuguese version: $\alpha=0.77)$.

The Oldenburg Inventory (OLBI) [54] was adapted for Portuguese students by Campos et al. [55] and seeks to evaluate their level of burnout. The inventory consists of 15 items and includes two subscales: the exhaustion subscale and the disengagement subscale. In the Portuguese version [55], the internal consistency of the exhaustion subscale was $\alpha=.565$ and the disengagement subscale was $\alpha=.700$.

\subsection{Statistical Analysis}

The data were analyzed using the SPSS® Statistics software (version 26, IBM, Armonk, NY, USA). Separate multiple linear regressions were done for each outcome (disengagement burnout and exhaustion burnout). The regressions assumptions were checked. To decide which variables would be included in each multiple linear regression, simple linear regressions were performed for each of the variables: gender, age, civil status (married or de facto union; divorced or single), has children, academic year, attending the academic year for the $1^{\text {st }}$ time, public institution of secondary education, special status, being away from home, living with how many other people $(0 ; 1 ; 2 ; 3 ; 4$ or more), leaves the house how often (occasionally; $1-2$ times per week; more than 3 times per week), being involved in some kind of volunteering, possessing all means to keep up with classes, taking nutritional supplements or stimulants, getting regular physical exercise before the pandemic, extracurricular activities, stressful life event in the last year, psychological support in the last year, loss of a family member/friend, taking a COVID test (no, but would like to; no, doesn't want to; yes, has the result). All the variables correlated with outcomes with $p \leq 0.20$ in the simple linear regressions were included in the multiple linear regressions. In the analysis of the multiple linear regressions, $\mathrm{p} \leq 0.05$ was considered significant.

\section{Results}

Regarding psychological resilience, 129 students (28\%) demonstrate reduced resilience, $236(51 \%)$ moderate resilience and 97 (21\%) high resilience. The students sampled scored an average resilience of 129 with a standard deviation of 20 and a range of 54-174. Regarding perceived stress, the students scored an average of 21 with a standard deviation of 7 and a range of 2-38. As for life satisfaction, the median score of the students sampled was 20, with a range of 5-25. Finally, regarding burnout, the students scored an average of 40 with a standard deviation of 7 and a range of 22-61.

An extensive representation of the results obtained is shown in Tables 2 and 3. The model used consists of four steps: in the first, all independent variables were adjusted through the multiple linear regression, and of these, those that were shown to be associated with exhaustion burnout for $p \leq 0.2$ were selected (Step 1). Then, stress was inserted (Step 2), followed by resilience (Step 3a) and satisfaction with life (Step 3b). In Step 4, the analysis is run with all the variables of the previous steps included.

\subsection{The mediating effect of resilience and life satisfaction on the relationship between stress and exhaustion burnout}

The mediating role of resilience and life satisfaction on the relationship between stress and exhaustion burnout (outcome) was ascertained by means of linear regression analyses (Table 2). The selected variables were age, gender, civil status, has children, academic year, special status, leaves the house how often, means, use of supplements and stimulants, physical exercise, extracurricular activities, stressful life event, psychological support, has taken a COVID test. The model obtained (Figure 1) demonstrated a positive association between exhaustion burnout and stress $(\beta=0.329 \mathrm{p}<0.05)$ and a negative association between resilience $(\beta=-0.03 p<0.05)$ and life satisfaction $(\beta=-0.13 p<0.05)$ and exhaustion burnout. In addition, there was a decrease in the association between stress 
and exhaustion burnout when analyzed with resilience and life satisfaction $(\beta=0.26 \mathrm{p}<$ $0.05)$.

Table 2. Results of multiple linear regressions (outcome: burnout exhaustion).

\begin{tabular}{llllll}
\hline & Step 1 $(\boldsymbol{\beta})$ & Step 2 $(\boldsymbol{\beta})$ & Step 3a $(\boldsymbol{\beta})$ & Step 3b $(\boldsymbol{\beta})$ & Step 4 $(\boldsymbol{\beta})$ \\
\hline $\begin{array}{l}\text { Male gender } \\
\text { Age }\end{array}$ & -1.289 & -0.226 & -0.337 & -0.407 & -0.443 \\
Civil status & -0.0015 & 0.078 & 0.086 & 0.05 & 0.063 \\
$\quad$ & & & & \\
$\quad$ Married or de facto union & Ref & Ref & Ref & Ref & Ref \\
$\quad$ Divorced or single & 3.37 & 1.884 & 2.084 & 1.748 & 1.937 \\
Has children & 2.23 & -0.819 & -0.488 & -0.578 & -0.391 \\
Academic year & -0.198 & -0.131 & -0.164 & -0.508 & -0.175 \\
Special status & -0.852 & -0.476 & -0.493 & -0.608 & -0.585 \\
Leaves the house how often & & & & & \\
$\quad$ Occasionally & Ref & Ref & Ref & Ref & Ref \\
$\quad$ 1-2 times per week & -0.452 & -0.375 & -0.389 & -0.258 & -0.3 \\
$\quad$ Z3 times per week & -0.678 & -0.385 & -0.337 & -0.358 & -0.329 \\
Means to keep up with classes & -2.107 & -0.577 & -0.496 & -0.753 & -0.644 \\
Supplements/stimulants & 0.991 & 0.317 & 0.389 & 0.371 & 0.411 \\
Physical exercise & -1.578 & -1.099 & -0.887 & -1.08 & -0.924 \\
Extracurricular activities & -0.467 & -0.391 & -0.227 & -0.197 & -0.124 \\
Stressful life event & 1.121 & 0.197 & -0.206 & 0.124 & 0.15 \\
Psychological support & 1.674 & 0.776 & 0.527 & 0.575 & 0.439 \\
Has taken a COVID test & & & & & \\
$\quad$ No, but would like to & Ref & Ref & Ref & Ref & Ref \\
$\quad$ No, doesn't want to & -0.664 & -0.515 & 0.466 & -0.614 & -0.049 \\
$\quad$ Yes, has the result & 0.757 & -0.09 & -0.158 & -0.158 & -0.55 \\
Stress & & 0.329 & 0.276 & & 0.258 \\
Resilience & & & -0.039 & & -0.029 \\
Life satisfaction & & & & -0.17 & -0.215 \\
& & & & & \\
\hline
\end{tabular}

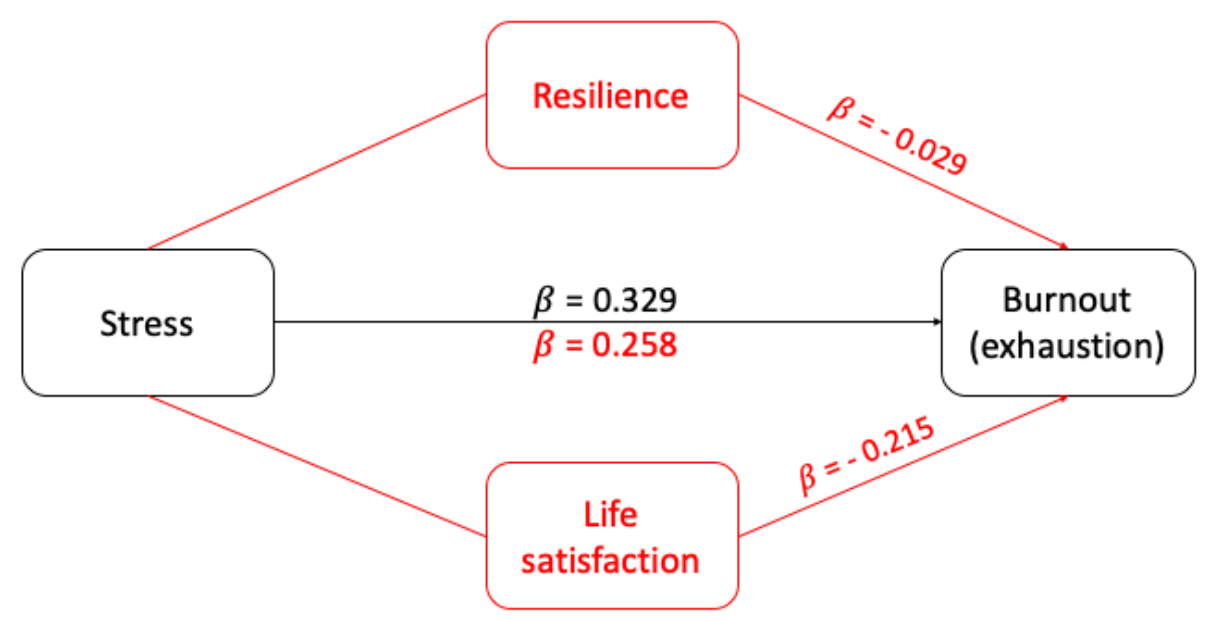

Figure 1. Diagram representing the modulating role of resilience and life satisfaction on the relationship between stress and exhaustion burnout. Changes in the value of beta when the modulator is present are noted in red. 
3.2. Mediating effect of resilience and life satisfaction on the relationship between stress and disengagement burnout

The mediating role of resilience and life satisfaction on the relationship between stress and disengagement burnout (outcome) was ascertained by means of linear regression analyses (Table 3). The selected variables included age, academic year, special status, leaves the house how often, volunteering, means, use of supplements, physical exercise, stressful life event and psychological support. The model obtained (Figure 2) showed a positive association between disengagement burnout and stress $(\beta=0.164, \mathrm{p}<0.05)$ and a negative association between resilience $(\beta=-0.04 \mathrm{p}<0.05)$ and life satisfaction $(\beta=-0.12 \mathrm{p}$ $<0.05$ ) and disengagement burnout. Similar to the previous case, there was a decrease in the association between stress and disengagement burnout when analyzed with resilience and life satisfaction $(\beta=0.08 \mathrm{p}<0.05)$.

Table 3. Multiple linear regression results (outcome: burnout distancing).

\begin{tabular}{llllll}
\hline & Step 1 $(\boldsymbol{\beta})$ & Step 2 $(\boldsymbol{\beta})$ & Step 3a $(\boldsymbol{\beta})$ & Step 3b $(\boldsymbol{\beta})$ & Step 4 $(\boldsymbol{\beta})$ \\
\hline Age & -0.02 & 0.012 & 0.023 & -0.012 & 0.006 \\
Academic year & -0.203 & -0.097 & $-0,139$ & -0.139 & -0.159 \\
Special status & -0.887 & -0.707 & -0.69 & -0.793 & -0.749 \\
Leaves the house how often & & & & & \\
$\quad$ Occasionally & Ref & Ref & Ref & Ref & Ref \\
$\quad$ 1-2 times per week & 0.077 & 0.132 & 0.113 & 0.257 & 0.198 \\
$\quad$ Z3 times per week & -0.517 & -0.319 & -0.253 & -0.296 & -0.251 \\
Volunteering & -0.606 & -0.45 & -0.469 & -0.356 & -0.404 \\
Means to keep up with classes & -1.085 & -0.339 & -0.198 & -0.513 & -0.338 \\
Supplements/stimulants & -0.535 & 0.227 & 0.292 & 0.244 & 0.29 \\
Physical exercise & -0.538 & -0.291 & 0.001 & -0.255 & -0.031 \\
Stressful life event & 0.921 & 0.447 & 0.463 & 0.369 & 0.409 \\
Psychological support & 0.486 & -0.03 & $-0,319$ & -0.219 & -0.388 \\
Stress & & 0.164 & 0.097 & 0.121 & 0.082 \\
Resilience & & & -0.05 & & -0.04 \\
Life satisfaction & & & & -0.187 & -0.122 \\
\hline
\end{tabular}

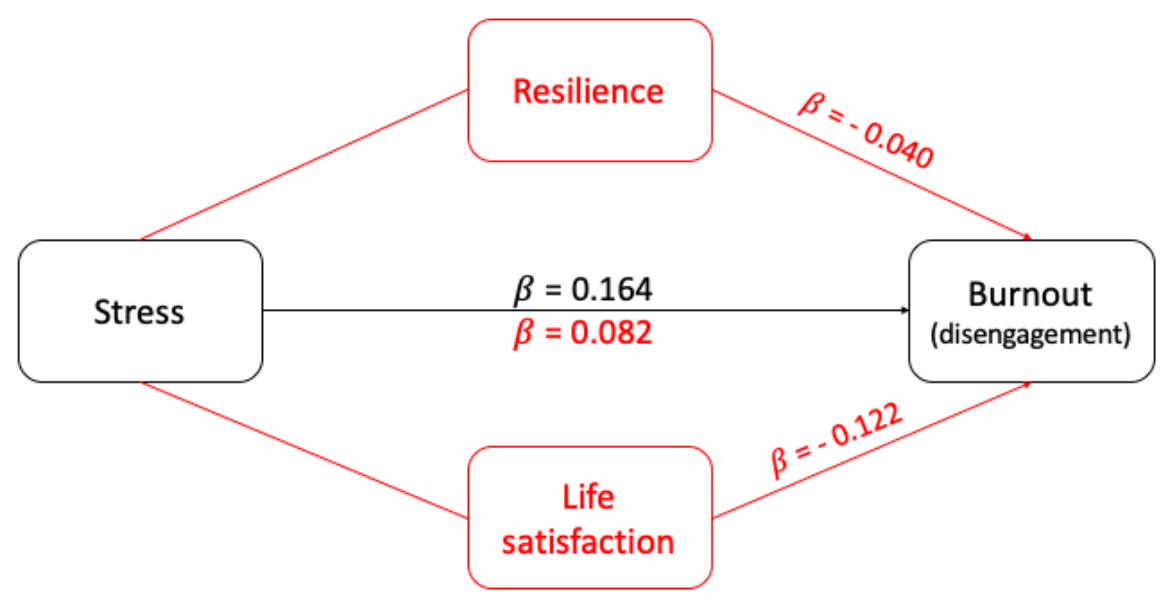

Figure 2. Diagram representing the modulating role of resilience and life satisfaction on the relationship between stress and disengagement burnout. Changes in the value of beta when the modulator is present are noted in red.

\section{Discussion}


The goal of the present study was to analyze the potential mediating roles of resilience and satisfaction with life on the relationship between perceived stress and burnout among medical students in the context of COVID-19. Indeed, in addition to the academic workload and responsibilities students bear as future health professionals with minimal margin for error, the epidemiological environment became another stress factor in undergraduate medical training $[17,18]$. For this reason, resilience and life satisfaction may have an impact on symptoms of anxiety, the subjective perception of well-being and, primarily, can function as protective variables against situations of burnout [36, 37]. This study therefore presented the hypothesis that resilience and life satisfaction could mediate the association between perceived stress and burnout. In this case, two dimensions were considered: "disengagement burnout", referring to burnout that manifests as a negative, cynical and disconnected response to others; and "exhaustion burnout", referring to the loss of emotional resources resulting in mental and physical fatigue, lack of energy to complete tasks and a sense of inability to restore one's energy $[5,56]$.

Our study indicates that half of medical students have high life satisfaction. In comparison, students at the University of the Azores (Portugal) demonstrated average levels of life satisfaction [57].

With respect to psychological resilience, it was observed that $72 \%$ of students have moderate or high resilience. Previous studies on students from other areas of health sciences, such as psychology and nursing, indicate moderate or slightly elevated values of resilience $(78 \%)$ [58].

In analyzing the results, it was found that the value of the standardized regression coefficient that relates stress with "disengagement burnout" decreased after including resilience in the model and when adjusted for life satisfaction. This demonstrates that resilience and life satisfaction play a mediating role in the association between stress and "disengagement burnout", with resilience exerting greater influence. These results are in alignment with previous studies indicating that resilience plays a role in managing emotions [56]. Considering the intrinsic characteristics of the medical profession and the demands inherent to caring for patients, it must be noted that this disengagement will have repercussions on the humane treatment and support of the patient. Thus, as expected, resilience and life satisfaction are negatively and significantly associated with stress and "disengagement burnout".

As regards the coefficient value of the standardized regression relating stress with "exhaustion burnout", a decrease was observed after including resilience in the model and when adjusted for life satisfaction. Therefore, it is once again underscored that resilience and life satisfaction negatively influence the association between stress and "exhaustion burnout", with resilience exerting greater influence. These data reinforce what is described in the literature [36,37].

Previous models demonstrated that resilience and life satisfaction exert an influence on the association between stress and the various dimensions of burnout. However, there are other possible variables that could interfere, namely, the quality of social interactions, self-compassion and a sense of purpose [59].

This study demonstrates, therefore, the need for institutions of higher education to develop policies of health promotion and self-care [4], which could include, for example, offering course subjects aimed toward developing stress management skills and building resilience [59]. Another example might be offering psychoeducational mindfulness programs to increase psychological flexibility and resilience or taking action to raise awareness among this group in particular of the need to implement self-care strategies and the effects these can have on their role as care takers. These measures are even more important for preventing burnout in situations like the COVID-19 pandemic. Effectively, the psychological, social and economic impact that the epidemiological context carries makes it an additional stress factor, for which resilience is a tool that can help prevent burnout among medical students. All the findings of this study have contributed toward the understanding of the relationship between resilience, life satisfaction, stress and burnout, and have 
established that resilience and life satisfaction appear to be important factors in fighting burnout among future doctors.

Finally, our study has some limitations. First, it is based on an online survey shared through email and social networks and may therefore have been affected by a selection bias. In other words, students who have easier digital access or who are more aware of the topic may have been more likely to respond. Furthermore, this was a transversal study, so the temporal interpretation of the data must be done with care. In this sense, given that these data refer to a specific and early period in the pandemic, it is also important to conduct a longitudinal study evaluating these effects in the long term, as well as to broaden the study to other Portuguese medical schools. Finally, it is suggested that there may be other variables affecting the relationship between stress and burnout; therefore, it could be useful to evaluate these variables in future studies.

\section{Conclusions}

Burnout is a syndrome resulting from dimensions like exhaustion, which emerges as a consequence of intense emotional or physical pressure, in any occupational context, and disengagement, which involves distancing from and a lack of identification with the surrounding environment. With resilience being defined as the ability to maintain a state of equilibrium in response to stress, whereby goals are achieved with a minimum of psychological and physical distress, it has become pertinent to evaluate the way resilience and life satisfaction may influence and mediate the association between perceived stress and burnout among medical students in the context of the COVID-19 pandemic.

This study has shown that when resilience and life satisfaction are analyzed in the association between stress and "disengagement burnout" and between stress and "exhaustion burnout", there is a decrease in the relationship between stress and burnout. Despite these two variables having had a greater impact on the reduction related to "disengagement burnout", the reduction in the two associations suggests that, despite stress and burnout having a clearly positive association, the association can be minimized through mechanisms that promote resilience and greater life satisfaction.

Therefore, knowing that medical students are an emotionally vulnerable population with greater levels of stress and anxiety, and that resilience is associated with less burnout and greater tolerance for uncertainty, our study complements other existing studies in demonstrating that, in the current pandemic context that has greatly compromised mental health, the promotion of institutional strategies to help develop mechanisms of adaptation to adverse events, as well as strategies to support students' physical and psychological well-being based on resilience, improved perception of life satisfaction and self-care, are fundamental.

Author Contributions: Conceptualization, I.D and C.S.S, methodology, I.D. and C.S.; formal analysis, C.S.; A.A. and A.F.; writing, review and editing, B.S.; J.S.; J.P.; P.D; B.C.; P.N., I.D. and C.S.S.; supervision, I.D.; C.S.S. and C.S; funding acquisition, I.D. All authors have read and agreed to the published version of the manuscript.

Funding: This article was supported by National Funds through FCT-Fundação para a Ciência e a Tecnologia, I.P., within CINTESIS, R\&D Unit (reference UIDB/4255/2020) and FCT, under the scope of the project UIDB/05198/2020 (Centre for Research and Innovation in Education, inED).

Institutional Review Review Board Statement: The study was conducted according to the guidelines of the Declaration of Helsinki, and approved by an independent Ethical Committee, Ethics Committee of São João Center (ref.98/2020).

Informed Consent Statement: Informed consent was obtained from all subjects involved in the study.

Data Availability Statement: The exact data can be obtained from the corresponding author.

Acknowledgments: We would like to thank all student participants for the time they dedicated to this study. 
Conflicts of Interest: The authors declare no conflicts of interest.

\section{References}

1. Chahrour, M.; Assi, S.; Bejjani, M.; Nasrallah, A.A.; Salhab, H.; Fares, M.Y.; Khachfe, H.H. A Bibliometric Analysis of COVID-19 Research Activity: A Call for Increased Output. Cureus 2020, 12, e7357, doi:10.7759/cureus.7357.

2. World Health Organization. Coronavirus disease (COVID-19) pandemic. Available online: (accessed on 05 Abril).

3. Ozamiz-Etxebarria, N.; Idoiaga Mondragon, N.; Dosil Santamaría, M.; Picaza Gorrotxategi, M. Psychological Symptoms During the Two Stages of Lockdown in Response to the COVID-19 Outbreak: An Investigation in a Sample of Citizens in Northern Spain. Frontiers in Psychology 2020, 11, doi:10.3389/fpsyg.2020.01491.

4. Miguel, C.; Castro, L.; Santos, J.P.M.; Serrão, C.; Duarte, I. Impact of COVID-19 on medicine lecturers' mental health and emergency remote teaching challenges. . Int. J. Environ. Res. Public Health 2021, 18, x. https://doi.org/10.3390/ ijerph18136792

5. Zis, P.; Artemiadis, A.; Bargiotas, P.; Nteveros, A.; Hadjigeorgiou, G.M. Medical studies during the COVID-19 pandemic: the impact of digital learning on burnout and mental health. 2020, doi:10.21203/rs.3.rs-63097/v1.

6. Lyons, Z.; Wilcox, H.; Leung, L.; Dearsley, O. COVID-19 and the mental well-being of Australian medical students: impact, concerns and coping strategies used. Australasian Psychiatry 2020, 28, 649-652, doi:10.1177/1039856220947945.

7. Moffat, K.J.; McConnachie, A.; Ross, S.; Morrison, J.M. First year medical student stress and coping in a problem-based learning medical curriculum. Medical Education 2004, 38, 482-491, doi:10.1046/j.1365-2929.2004.01814.x.

8. McGuire, F.L. Psycho-social studies of medical students. Academic Medicine 1966, 41, 424-445, doi:10.1097/00001888196605000-00002.

9. Voltmer, E.; Kötter, T.; Spahn, C. Perceived medical school stress and the development of behavior and experience patterns in German medical students. Medical Teacher 2012, 34, 840-847, doi:10.3109/0142159x.2012.706339.

10. Schwenk, T.L.; Davis, L.; Wimsatt, L.A. Depression, Stigma, and Suicidal Ideation in Medical Students. JAMA 2010, 304, 1181, doi:10.1001/jama.2010.1300.

11. Dyrbye, L.N.; Thomas, M.R.; Shanafelt, T.D. Medical Student Distress: Causes, Consequences, and Proposed Solutions. Mayo Clinic Proceedings 2005, 80, 1613-1622, doi:10.4065/80.12.1613.

12. Dyrbye, L.N.; Schwartz, A.; Downing, S.M.; Szydlo, D.W.; Sloan, J.A.; Shanafelt, T.D. Efficacy of a Brief Screening Tool to Identify Medical Students in Distress. Academic Medicine 2011, 86, 907-914, doi:10.1097/acm.0b013e31821da615.

13. Saraswathi, I.; Saikarthik, J.; Senthil Kumar, K.; Madhan Srinivasan, K.; Ardhanaari, M.; Gunapriya, R. Impact of COVID19 outbreak on the mental health status of undergraduate medical students in a COVID-19 treating medical college: a prospective longitudinal study. PeerJ 2020, 8, e10164, doi:10.7717/peerj.10164.

14. Jennings, M. Medical Student Burnout: Interdisciplinary Exploration and Analysis. Journal of Medical Humanities 2009, 30, 253-269.

15. Freudenberger, H.J. Staff Burn-Out. Journal of Social Issues 1974, 30, 159-165, doi:10.1111/j.1540-4560.1974.tb00706.x.

16. Organization, W.H. Burn-out an "occupational phenomenon": International Classification of Diseases 2019. Available online: https://www.who.int/news/item/28-05-2019-burn-out-an-occupational-phenomenon-international-classification-ofdiseases (accessed on $26^{\text {th }}$ July 2021).

17. Almeida, G.d.C.; Souza, H.R.d.; Almeida, P.C.d.; Almeida, B.d.C.; Almeida, G.H. The prevalence of burnout syndrome in medical students. Archives of Clinical Psychiatry (São Paulo) 2016, 43, 6-10, doi:10.1590/0101-60830000000072.

18. Shanafelt, T.D.; Dyrbye, L.N.; West, C.P.; Sinsky, C.A. Potential Impact of Burnout on the US Physician Workforce. Mayo Clinic Proceedings 2016, 91, 1667-1668, doi:10.1016/j.mayocp.2016.08.016.

19. Molodynski, A.; Lewis, T-; Kadhum, M.; Farrell, S.; M.; Chelieh, M.; L.; Almeida, T.; Masri, R.; Kar, A.; Volpe, U.; Moir, F.; Torales, J.; Castaldelli-Maia, J.; Chau, S.; W.; H.; Wilkes,C.; Bhugra, D. Cultural variations in wellbeing, burnout and 
substance use amongst medical students in twelve countries, International Review of Psychiatry, 2021, 33:12, 3742, DOI: 10.1080/09540261.2020.1738064.

20. Maslach, C.; Jackson, S. E.; Leiter, M. P. Maslach Burnout Inventory Manual 2016, $4^{\text {th }}$ Edn. Menlo Park, CA: Mind Garden. Available online at: https://www.mindgarden.com.

21. Demerouti, E.; Bakker, A. B.; Vardakou, I.; Kantas, A. The convergent validity of two burnout instruments: a multitraitmultimethod analysis. Eur. J. Psychol. Assess. 2003, 19, 12-23, doi: 10.1027//1015-5759.19.1.12.

Kristensen, T.S.; Borritz, M.; Villadsen, E.; Christensen, K.B. The Copenhagen Burnout Inventory: a new tool for the assessment of burnout. Work Stress 2005, 19, 192-207, doi: 10.1080/02678370500297720.

23. Schaufeli W.; B.; Leiter, M.; P.; Maslach, C.; Jackson, S.; E. Maslach burnout inventory - General survey C. Maslach, S.E. Jackson, M.P. Leiter(Eds.), The Maslach Burnout Inventory-Test Manual, Consulting Psychologists Press, Palo Alto, CA 1996, pp. 19-26.

24. Halbesleben, J. R. B.; Demerouti, E. The construct validity of an alternative measure of burnout: investigating the English translation of the Oldenburg Burnout Inventory. Work Stress 2005, 19, 208-220, doi: 10.1080//02678370500340728.

25. Demerouti, E.; Bakker, A.; B.; Vardakou, I.; Kantas, A. The convergent validity of two burnout instruments European Journal of Psychological Assessment 2003, 19 (1) , pp. 12-23, doi: 10.1027//1015-5759.19.1.12.

26. Demerouti, E; Mostert, K.; Bakker, A.; K. Burnout and work engagement: A thorough investigation of the independency of both constructs. Journal of Occupational Health Psychology 2010, 15 (3), pp. 209-222, doi: 10.1037/a0019408. Reis, D.; Xanthopoulou, D.; Tsaousis, I. Measuring job and academic burnout with the Oldenburg Burnout Inventory (OLBI): Factorial invariance across samples and countries. Burnout Research 2015 2(1), 8-18, doi: 10.1016/j.burn.2014.11.001.

Demerouti, E; Nachreiner, F. Zur spezifitat von burnout fur dienstleistungsberufe: Fakt oder artefakt? [The specificity of burnout in human services:Fact or artifact?] Z. Arbeitswiss 1998, 52, 82-89.

29. Campos, J.; A.; D.; B.; Carlotto, M.; S.; Marôco, J. Oldenburg Burnout Inventory-student version: cultural adaptation and <avalidation into Portuguese. Psicol. Reflex. Crít. 2012, 25, 709-718, doi: 10.1590/S0102-79722012000 400010.

30. Wing, T.; Pey, YC; Subramaniam, V.; Ab Raof NA ; Ting OW; and Ahmad MHH, Prevalence of Burnout in Medical and Non-medical Undergraduate Malaysian Students in Various International Universities - A Cross Sectional Study. J. Adv. Med. Res., 2018, pp.1-13, doi: 10.9734/JAMMR/2018/40212.

31. Ishak, WW; Nikravesh, R; Lederer, S.; Perry, R.; Ogunyemi, D.; Bernstein, C. Burnout in medical students: A systematic review. Clin .Teach. 2013, 10, 242-245, doi: 10.1111/tct.12014.

32. West, C.P.; Dyrbye, L.N.; Sinsky, C.; Trockel, M.; Tutty, M.; Nedelec, L.; Carlasare, L.E.; Shanafelt, T.D. Resilience and Burnout Among Physicians and the General US Working Population. JAMA Netw. Open 2020, 3, e209385, doi:10.1001/jamanetworkopen.2020.9385.

33. Keeton K.; Fenner, D.; Johnson, T.; Hayward, R. Predictors of physician career satisfaction, work-life balance, and burnout. Obstet Gynecol. 2007; 109: 949-55, doi: 10.1097/01.AOG.0000258299.45979.37.

34. Gheihman, G.; Cooper, C.; Simpkin, A. Everyday Resilience: Practical Tools to Promote Resilience Among Medical Students. Journal of General Internal Medicine 2018, 34, 498-501, doi:10.1007/s11606-018-4728-8.

35. Wagnild, G.M.; Young, H.M. Development and psychometric evaluation of the Resilience Scale. J Nurs Meas 1993, 1, 165178.

36. Wright, B.; Richmond Mynett, J. Training medical students to manage difficult circumstances- a curriculum for resilience and resourcefulness? BMC Medical Education 2019, 19, doi:10.1186/s12909-019-1712-x.

37. Lin, Y.K.; Lin, C.-D.; Lin, B.Y.-J.; Chen, D.-Y. Medical students' resilience: a protective role on stress and quality of life in clerkship. BMC Medical Education 2019, 19, doi:10.1186/s12909-019-1912-4. 
38. Jordan, R.K.; Shah, S.S.; Desai, H.; Tripi, J.; Mitchell, A.; Worth, R.G. Variation of stress levels, burnout, and resilience throughout the academic year in first-year medical students. PLOS ONE 2020, 15, e0240667, doi:10.1371/journal.pone.0240667.

39. Serrão, C.; Castro, L.; Teixeira, A.; Rodrigues, A.R.; Duarte, I. Resilience in Physicians: Contributions to the Validation of the European Portuguese Version of the Resilience Scale. 2021 2021, 34, 10, doi:10.20344/amp.14657.

40. Jenkins, T.M.; Kim, J.; Hu, C.; Hickernell, J.C.; Watanaskul, S.; Yoon, J.D. Stressing the journey: using life stories to study medical student wellbeing. Advances in Health Sciences Education 2018, 23, 767-782, doi:10.1007/s10459-018-9827-0.

41. Mavor, K.I.; McNeill, K.G.; Anderson, K.; Kerr, A.; O'Reilly, E.; Platow, M.J. Beyond prevalence to process: the role of self and identity in medical student well-being. Medical Education 2014, 48, 351-360, doi:10.1111/medu.12375.

42. Thompson, G.; McBride, R.B.; Hosford, C.C.; Halaas, G. Resilience Among Medical Students: The Role of Coping Style and Social Support. Teaching and Learning in Medicine 2016, 28, 174-182, doi:10.1080/10401334.2016.1146611.

43. Rahimi, B.; Baetz, M.; Bowen, R.; Balbuena, L. Resilience, stress, and coping among Canadian medical students. Can Med Educ J. 2014; 5(1):e5-e12.

44. Dyrbye, L.N.; Power, D.V.; Massie, F.S.; Eacker, A.; Harper, W.; Thomas, M.R.; Szydlo, D.W.; Sloan, J.A.; Shanafelt, T.D. Factors associated with resilience to and recovery from burnout: a prospective, multi-institutional study of US medical students. Medical Education 2010, 44, 1016-1026, doi:10.1111/j.1365-2923.2010.03754.x.

45. Yu, J.; Chae, S. The mediating effect of resilience on the relationship between the academic burnout and psychological wellbeing of medical students. Korean Journal of Medical Education 2020, 32, 13-21, doi:10.3946/kjme.2020.149.

46. McLuckie, A.; Matheson, K.M.; Landers, A.L.; Landine, J.; Novick, J.; Barrett, T.; Dimitropoulos, G. The Relationship Between Psychological Distress and Perception of Emotional Support in Medical Students and Residents and Implications for Educational Institutions. Academic Psychiatry 2017, 42, 41-47, doi:10.1007/s40596-017-0800-7.

47. Cho, E.; Jeon, S. The role of empathy and psychological need satisfaction in pharmacy students burnout and well-being. BMC Med Edu 2019, 19, 43, /doi.org/10.1186/s12909-019-1477-2.

48. Hopkins, L.; Morgan, H.; Buery-Joyner, S.D.; Craig, L.B.; Everett, E.N.; Forstein, D.A.; Graziano, S.C.; Hampton, B.S.; McKenzie, M.L.; Page-Ramsey, S.M.; et al. To the Point: a prescription for well-being in medical education. American Journal of Obstetrics and Gynecology 2019, 221, 542-548, doi:10.1016/j.ajog.2019.05.012.

49. Marina, S.; Duarte, I.; Ricou, M. Informed consent in clinical research in Portugal: promotion of good practices. Acta Méd Port. 2020, 33(7-8), 453-5. doi: 10.20344/amp.13545.

50. Trigo, M.; Canudo, N.; Branco, F.; Silva, D. Estudo das propriedades psicométricas da Perceived Stress Scale (PSS) na população portuguesa. Psychologica 2010, 53, 353-378. https://doi.org/10.14195/1647-8606_53_17

51. Oliveira, M.; Sousa Machado, T. Tradução e validação da Escala de Resiliência para Estudantes do Ensino Superior. Análise Psicológica 2011, 29, 579-591, doi:10.14417/ap.105.

52. Diener, E.D.; Emmons, R.A.;Larsen, R.J.; Griffin S. The satisfaction with life scale. J Pers Assess. 1985, 49, 71-5.

53. Simões, A. Ulterior validação de uma escala de satisfação com a vida (SWLS) [Validation of a life satisfaction scale]. Rev Portuguesa Pedagogia. 1992, 26(3), 503-515.

54. Halbesleben, J. R. B., \& Demerouti, E. (2005). The construct validity of an alternative measure of burnout: Investigating the English translation of the Oldenburg Burnout Inventory. Work and Stress 2005, 19(3), 208-220. doi: 10.1080/02678370500340728.

55. Campos, J.A.D.B.; Carlotto, M.S.; Marôco, J. Oldenburg Burnout Inventory-student version: cultural adaptation and validation into Portuguese. Psicol. Reflex. Crít. 2012, 25, 709-718. doi: 10.1590/S0102-79722012000400010

56. Maslach, C.; Jackson, S.E. The measurement of experienced burnout. Journal of Organizational Behavior 1981, 2, 99-113, doi:10.1002/job.4030020205. 
57. Caldeira, S.N.; Sousa, A. Satisfação com a vida e envolvimento académicono ensino superior [Satisfaction with lifeand student engagement in higher education]. Atas do II Congresso Internacional Envolvimento dos Alunos na Escola: Perspetivas da Psicologia e Educação, Motivação para o desempenho académico 2016, 893-906. ISBN: 978-989-8753-35-9.

58. Dias, J.; Magalhães, A.; Oliveira, A.; Silva, B.; Macedo, S.; Santos, I.M. Burnout, personalidade e desregulação emocional em professores do ensino superior [Burnout, personality and emotional dysregulation in teachers of higher education]. Actas do 3ํㅡㄹ Congresso da Ordem dos Psicólogos Portugueses 2017, 299-311.

59. Serrão, C.; Duarte, I.; Castro, L.; Teixeira, A. Burnout and Depression in Portuguese Healthcare Workers during the COVID19 Pandemic-The Mediating Role of Psychological Resilience. Int. J. Environ. Res. Public Health 2021, $18,636$. https://doi.org/10.3390/ijerph18020636. 